\title{
Índices topográficos aplicados à modelagem agrícola e ambiental
}

\author{
Topographic indexes applied to agricultural and environmental modelling
}

\author{
Jean Paolo Gomes Minella ${ }^{\mathrm{I}}$ Gustavo Henrique Merten ${ }^{\mathrm{II}}$
}

\section{- REVISÃO BIBLIOGRÁFICA -}

\section{RESUMO}

Índices topográficos (IT) obtidos computacionalmente a partir do modelo numérico de elevação do terreno (MNE) têm sido incorporados em algoritmos computacionais aplicados na simulação de processos hidrológicos, erosivos e de transporte de poluentes. Por meio desses índices, zonas de acúmulo de umidade em uma bacia hidrográfica, por exemplo, podem ser previstas espacialmente através de IT, que levam em consideração efeitos de orientação de drenagem e declividade do terreno. Este trabalho tem como propósito o de apresentar uma revisão bibliográfica sobre esse tema e de demonstrar a aplicabilidade desses indices por meio de alguns exemplos, aplicada à modelagem agrícola e ambiental.

Palavras-chave: indices topográficos, modelagem agrícola e ambiental, bacias hidrográficas.

\section{ABSTRACT}

Topographic indices obtained computationally from the numerical model of elevation have been incorporated into computer algorithms and used in hydrological simulating processes, erosion and pollutant transport. Through these indices, zones of water accumulation in a catchment, for example, can be predicted using topographic index that take into account the slope orientation and land slope. This study aims to present a review of the literature on this topic by means of some examples applied in agricultural and environmental modelling.

Key words: topographic indexes, agricultural and environmental modelling, catchments.

\section{INTRODUÇÃO}

O planejamento das atividades agrícolas deve basear-se não apenas na aplicação do conceito de capacidade produtiva das terras, mas também em estudos que levem em consideração a importância ecológica e hidrológica de todos os componentes da paisagem (florestas, mata ciliar, banhados, etc.). A aplicação do Sistema Geográfico de Informações (SIG), combinado com o Modelo Numérico de Elevação (MNE), possibilita identificar na paisagem variáveis que descrevam processos hidrológicos, geomorfológicos e biológicos que são fundamentais para esse planejamento (MOORE et al., 1991).

Nesse contexto, a topografia assume uma função essencial, já que as características do relevo condicionam os fluxos de materiais (água, nutrientes, sedimentos e contaminantes) e energia na paisagem (MOORE et al., 1991). Tais características controlam a variabilidade espacial da umidade do terreno (MOORE, 1988), das características dos solos, do processo erosivo e da degradação do solo e da água (MOORE \& BURCH, 1986a). Essas características podem ser avaliadas por um número significativo de índices topográficos que são úteis para identificar a susceptibilidade ao dano e que podem ser estimados usando técnicas de análise digital do terreno a partir do MNE.

O presente trabalho tem como objetivo apresentar uma revisão bibliográfica sobre o assunto e

'Departamento de Solos, Universidade Federal de Santa Maria (UFSM), 97105-900, Santa Maria, RS, Brasil. E-mail: jminella@smail.ufsm.br. Autor para correspondência.

"Instituto de Pesquisas Hidráulicas, Universidade Federal do Rio Grande do Sul (UFRGS), Porto Alegre, RS, Brasil. 
resultados da aplicabilidade de técnicas de geomorfometria na modelagem agrícola e ambiental (MAA), através de índices topográficos primários e secundários, derivados do MNE. O trabalho utiliza informações de uma pequena bacia hidrográfica experimental $\left(1,19 \mathrm{~km}^{2}\right)$ para exemplificar as técnicas apresentadas e mostrar a potencialidade para o planejamento e MAA.

Geomorfometria e o planejamento agrícola e ambiental A magnitude dos processos hidrológicos, geomorfológicos e biológicos são sensíveís à posição topográfica, porém, na maioria dos casos, é difícil medir as variáveis necessárias para sua descrição, devido a sua variabilidade espacial. A possibilidade de se obter de maneira simples índices topográficos que representem adequadamente essas variáveis complexas é um dos desafios atuais da modelagem agrícola e ambiental(LONGLEY et al., 2005).

A análise de problemas ambientais é realizada por meio do entendimento de processos físicos, químicos, biológicos, econômicos e sociais que interagem no tempo e no espaço. Esses processos e suas interações são descritos matematicamente utilizando variáveis e parâmetros explicativos que são capazes de representar uma realidade com algum grau de simplificação (MENDES \& CIRILO, 2001; MEIRELLES et al., 2007). Contudo, muitos desses modelos ainda não possuem capacidade de análise espacialmente distribuída, ou então utilizam ferramentas pouco precisas ou inadequadas para as diferentes escalas de análise. Por isso, as técnicas de geoprocessamento possibilitam aos modelos se beneficiarem das capacidades analíticas e da apresentação de dados geográficos (MENDES \& CIRILO, 2001). O geoprocessamento permite estudar de maneira eficiente as feições geomorfológicas do relevo, consequentemente, a sua integração com modelos ambientais resulta em grandes benefícios para a descrição dos processos e, consequentemente, com o planejamento e gerenciamento dos recursos naturais (ARONOFF, 1995).

O modelo numérico do terreno (MNT) é uma representação matemática da distribuição espacial de uma determinada característica, vinculada a uma superfície real, sendo que o Modelo Numérico de Elevação (MNE) é termo usado para a representação de altimetria (BURROUGH, 1987; LONGLEY et al., 2005). Os MNE são derivados de levantamentos de campo, digitalização de mapas, medições fotogramétricas a partir de modelos estereoscópicos, dados altimétricos adquiridos por uso do Sistema de Posicionamento Global (GPS), missão topográfica por radar interferométrico (SRTM- Shuttle Radar Topography Mission).
Obtenção de índices topográficos primários

Atualmente, com o aumento na qualidade e na disponibilidade dos MNE, é possível analisar dados de elevação do terreno de uma forma rápida e eficiente. Uma das metodologias para quantificar o controle da topografia sobre processos físicos é a utilização de índices topográficos (WILSON \& GALLANT, 1996) que caracterizam atributos simples e complexos do terreno.

Os índices topográficos (IT) podem ser divididos em primários e secundários. Os índices topográficos primários (ITP) são calculados diretamente do MNE e representam as características básicas, como, por exemplo, declividade, aspecto e área acumulada; enquanto os índices topográficos secundários (ITS) são calculados por meio da combinação de dois ou mais índices primários e representam características mais complexas, como, por exemplo, umidade do solo ou potencial erosivo (MOORE et al., 1991). Eles são requeridos nos modelos ambientais como informação necessária para inúmeros procedimentos de cálculo, por exemplo, o uso do aspecto para o cálculo do balanço de energia, ou para representar processos de difícil medição, por exemplo, o uso da declividade e área acumulada para determinar as zonas de saturação de água na paisagem (RICHERSON \& LUN, 1980; QUINN et al., 1995; 2002). Os principais ITPs provenientes do MNE (Tabela 1) utilizados na modelagem matemática de inúmeros processos com aplicação no planejamento agrícola e ambiental são apresentados na tabela 1 (MOORE et al., 1991).

Adeclividade e o aspecto do terreno (Tabela 1) são ITP amplamente utilizados, eles exercem influência sobre o fluxo da água, processo erosivo, sombreamento, energia solar recebida, reflectância da superfície, temperatura, entre outras variáveis. A declividade do terreno é definida como a taxa de diminuição da altura na direção do aspecto, e o aspecto corresponde à direção de máximo gradiente (MENDES \& CIRILO, 2001).

O comprimento de rampa é outro IT muito importante, sendo definido como a distância máxima entre o divisor e o talvegue, ou entre o divisor e qualquer característica do relevo que altere a continuidade das linhas de fluxo, como terraços, cordão vegetado, estradas ou bordas de lavouras. O comprimento de rampa é utilizado para os estudos hidrológicos e erosivos em bacias hidrográficas, pois define $o$ comprimento dos fluxos preferenciais.

As variações do gradiente e do aspecto em uma determinada vertente definem a forma da vertente; existem duas classificações: a curvatura no plano e a curvatura no perfil (BEVEN \& KIRBY, 1979). A curvatura no plano representa a taxa de variação da declividade na direção ortogonal à do aspecto, sendo que esse 
Tabela 1 - Principais índices topográficos primários (ITP).

\begin{tabular}{|c|c|c|}
\hline Atributo & Definição & Aplicação \\
\hline Altitude & Elevação & Clima; Tipo de vegetação; Energia potencial \\
\hline Altura a montante & Altura média da área a montante & Energia potencial \\
\hline Aspecto & Direção do gradiente & Direção de fluxo; Irradiação solar \\
\hline Declividade & Gradiente & Volume e velocidade do escoamento \\
\hline Declividade a montante & $\begin{array}{l}\text { Declividade média de uma área a montante } \\
\text { de um ponto }\end{array}$ & Velocidade do escoamento \\
\hline Declividade da bacia & Declividade média de uma bacia & Tempo de concentração \\
\hline Área da bacia & Área de drenagem no exutório da bacia & Volume do escoamento \\
\hline Área de contribuição específica & $\begin{array}{l}\text { Área a montante dividida por unidade de } \\
\text { contorno }\end{array}$ & $\begin{array}{l}\text { Volume do escoamento; } \\
\text { Taxa de escoamento superficial }\end{array}$ \\
\hline Comprimento de fluxo & $\begin{array}{l}\text { Distância máxima do escoamento para um } \\
\text { ponto }\end{array}$ & $\begin{array}{l}\text { Erosão; Produção de sedimentos; Tempo de } \\
\text { concentração }\end{array}$ \\
\hline Comprimento a montante & $\begin{array}{l}\text { Comprimento médio dos comprimentos de } \\
\text { fluxos para um ponto na bacia }\end{array}$ & Aceleração do escoamento; Taxas de erosão \\
\hline Comprimento de dispersão & $\begin{array}{l}\text { Distância de um ponto até o exutório da } \\
\text { bacia }\end{array}$ & Impedância à drenagem do solo \\
\hline Comprimento da bacia & $\begin{array}{l}\text { Distância do ponto mais alto até o exutório } \\
\text { da bacia }\end{array}$ & Atenuação do escoamento superficial \\
\hline Curvatura no perfil & Curvatura do perfil de declividade & $\begin{array}{l}\text { Aceleração do escoamento; Taxas de erosão e } \\
\text { deposição }\end{array}$ \\
\hline Curvatura no plano & Curvatura do contorno & $\begin{array}{l}\text { Fluxo divergente ou convergente; Conteúdo de } \\
\text { água no solo }\end{array}$ \\
\hline Curvatura tangencial & $\begin{array}{l}\text { Curvatura do plano multiplicada pela } \\
\text { declividade }\end{array}$ & Fluxo divergente e convergente local \\
\hline
\end{tabular}

Fonte: adaptado de MOORE et al. (1991).

fator (curvatura no plano) tem sido relacionado com a umidade e o fluxo da água sobre o terreno (O`LOUGHLIN, 1986). De acordo com a curvatura no plano, uma encosta pode ser classificada como convergente, divergente ou reta. Terrenos convergentes são aqueles em que as direções de maior declividade em diferentes pontos do terreno tendem a convergir, terrenos divergentes são aqueles em que as direções de maior declividade em diferentes pontos tendem a divergir (MOORE et al., 1988)

A curvatura no perfil é a taxa de variação da declividade na direção do aspecto. A curvatura no perfil é decisiva na aceleração ou desaceleração do fluxo da água sobre o terreno e, portanto, influencia na velocidade do escoamento e, consequentemente, na erosão do solo e na propagação de sedimentos. Por meio da curvatura no perfil, é possível definir a morfologia de uma encosta, que pode ser côncava, convexa ou retilínea. Encostas côncavas são aquelas em que a declividade diminui na direção do aspecto, terrenos convexos são aqueles em que a declividade aumenta na direção do aspecto e terrenos retos são aqueles em que a declividade não se altera (FLORINSKY, 2000). Nas encostas convexas, ocorre um progressivo aumento do potencial erosivo ao longo da encosta. Já na condição de encostas côncavas, o potencial erosivo é atenuado na direção do aspecto.

$\mathrm{O}$ índice topográfico, denominado área de contribuição específica $\left(\mathrm{A}_{\mathrm{s}}\right)$, é definido como a área de contribuição dividida pela largura do contorno. Esse índice é uma medida que representa o volume potencial do escoamento superficial em dado ponto da vertente. Tal parâmetro integra os efeitos da área de contribuição a montante e os efeitos da convergência ou divergência sobre o escoamento (curvatura no plano).

Cálculo e aplicação de índices topográficos secundários Os ITS têm sido utilizados na modelagem de processos hidrológicos, geomorfológicos e biológicos, para obter informações da discretização espacial de processos que são de difícil medição direta em áreas de grande extensão. Neste item, serão apresentados três ITS utilizados na modelagem agrícola e ambiental. Primeiramente, será apresentado o cálculo do fator LS utilizado no modelo matemático de predição de erosão Equação Universal de Perdas de Solo - USLE. Posteriormente, será demonstrado o cálculo da potência do escoamento, utilizado para identificar áreas com 
potencial de formação de erosão do tipo sulcos, ravinas, voçorocas. Finalmente, será apresentado o índice de umidade do terreno, que tem sido relacionado com as zonas de saturação e, portanto, consideradas áreas preferenciais de formação do escoamento superficial e maior umidade do terreno.

a) Determinação do índice topográfico da USLE

Nas últimas décadas, parte da modelagem do processo erosivo na escala de lavoura tem sido dominada pelos modelos empíricos baseados na USLE e RUSLE (Revised Universal Soil Loss Equation) (RENARD et al., 1994), inclusive para a escala de bacia, em que o processo erosivo é abordado por meio de modelos conceituais do tipo SWAT (Soil and Water Assesment Tool), EPIC (Erosion-Productivity Impact Calculator), AGNPS (Agricultural Non-Point Source Pollution Model). É importante salientar, no entanto, que a USLE foi desenvolvida para ser aplicada em pequena escala (lavouras), na qual a unidade de relevo é homogênea ou uniforme (MORGAN, 2005). Essa condição, no entanto, não corresponde à realidade da maioria dos casos em que esses modelos têm sido aplicados. Por outro lado, a demanda por informações sobre o impacto da agricultura sobre os recursos naturais, modelos baseados na USLE, têm sido frequentemente utilizados nas grandes escalas (bacia hidrográfica), nas quais quase sempre o relevo é mais complexo na sua morfologia. Nesse caso, uma alternativa para a aplicação da USLE, na escala de bacia, é utilizar uma metodologia que incorpora na estrutura de cálculo do fator LS (Length Slope) a influência da forma das encostas (MINELLA et al., 2010). MOORE \& BURCH (1986b) e WILSON \& GALLANT (1996) deduziram um índice topográfico relacionado com a produção de sedimentos por unidade de área. Os parâmetros usados nessa relação incluem os dois elementos originais do fator topográfico $L S$ tradicional da USLE (declividade e comprimento de rampa), mas com uma importante contribuição que é a de considerar a forma da bacia. A partir disso, foi derivada uma expressão que utiliza dois índices topográficos primários $\left(\beta\right.$ e $\left.A_{s}\right)$ para calcular um ITS denominado de $\mathrm{T}_{\mathrm{c}}$, que representa a distribuição espacial da potencial perda de solo. $\mathrm{O}$ índice $\mathrm{T}_{\mathrm{c}}$ é escrito na forma:

$$
T_{c}=\left(A_{s} / 22,13\right)^{m} *(\operatorname{sen} \beta / 0,0896)^{n}
$$

em que $\mathrm{A}_{\mathrm{s}}$ corresponde à área de contribuição específica por unidade de largura ortogonal à linha de fluxo $\left(\mathrm{m}^{2} \mathrm{~m}^{-1}\right)$; $\beta$ o gradiente, com $m=0,6$ e $n=1,3$. O uso do $T_{c}$ gera melhores resultados na modelagem da perda de solos, pois inclui os fatores chave para a representação do processo hidrológico e erosivo desses ambientes (MINELLA et al., 2010).

O valor de $T_{c}$ foi obtido na bacia experimental de Arvorezinha - RS. Essa bacia tem 119ha e se caracteriza por apresentar um relevo declivoso, uma intensa atividade agrícola e intensa erosão hídrica com forte impacto sobre os recursos naturais (MERTEN \& MINELLA, 2005). Os dados básicos para gerar o mapa de erosão hídrica na bacia experimental do Lajeado Ferreira foram: a) curvas de nível geradas por restituição de foto aérea (1:10.000); b) dados de precipitação diária, obtidos através de várias estações meteorológicas próximas à bacia e do posto de monitoramento dentro da bacia; c) levantamento detalhado das unidades de solo; e d) levantamento do uso e do manejo do solo com a utilização do GPS. A figura 1 mostra o MNE da bacia com tamanho de célula de $25 \mathrm{~m}^{2}$, informação básica necessária para o cálculo do fator topográfico $\left(T_{c}\right)$ de forma distribuída na bacia.

O cálculo do fator $K$ foi realizado utilizandose o nomograma de Wischmeier (WISCHMEIER \& SMITH, 1978), utilizando dados de entrada a descrição e classificação dos solos da bacia (MERTEN \&

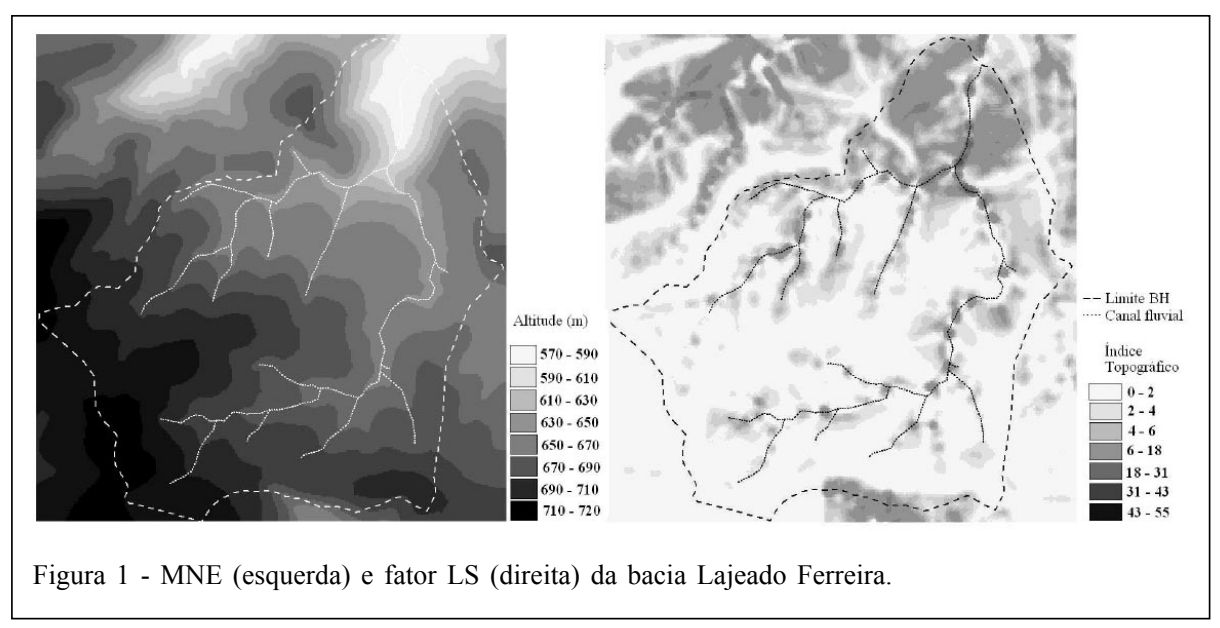

Ciência Rural, v.42, n.9, set, 2012. 
MINELLA, 2005), com valores de 0,033t ha h ha ${ }^{-1} \mathrm{MJ}^{-1}$ $\mathrm{mm}^{-1}$ para a associação Cambissolo e Neossolo e 0,016 para a classe Argissolo. Para o cálculo da erosividade mensal das chuvas, foram utilizadas séries de 30 anos de dados diários de precipitação de 12 estações pluviográficas na região de Arvorezinha (MERTEN \& MINELLA, 2005), com valor anual calculado de 6540 $\mathrm{MJmmha}^{-1} \mathrm{~h}^{-1} \mathrm{ano}^{-1}$, classificada como erosividade moderada a forte. Os fatores $C$ e $P$ foram determinados a partir do levantamento do uso e do manejo do solo na bacia; os valores do fator $C$ utilizados para os diferentes sistemas de cultivo em sucessão foram calculados segundo o método proposto por SEAA (1994), considerando a variabilidade interanual das culturas e o índice de erosividade (BENATTO et al., 2006).

Tendo calculado todos os fatores necessários para a aplicação da Equação Universal de Perda de Solo (USLE) (WISCHMEIER \& SMITH, 1978), foi realizada a multiplicação dos fatores (mapas na forma matricial) e obtido o mapa final de erosão hídrica. A erosão hídrica total na bacia foi de $1.756 \mathrm{tano}^{-1}$, o que representa um valor médio por hectare de $15 \mathrm{t} \mathrm{ano}^{-1}$. Os resultados demonstram que a simulação da USLE acoplada em um SIG representa uma importante ferramenta no planejamento agrícola e ambiental na bacia, pois possibilita identificar as áreas com maior risco de erosão e, portanto, mais suscetíveis à degradação do solo. A partir da identificação dessas áreas, é possível orientar a implantação de práticas de conservação e manejo do solo para que essas sejam mais eficientes no controle da erosão hídrica.

b) Determinação do índice da potência do escoamento

A erosão hídrica na escala de bacia hidrográfica ocorre de várias maneiras, principalmente: a) erosão entressulcos e em sulcos na bacia vertente; b) em ravinas ou voçorocas; e c) a erosão no canal fluvial. Por outro lado, os modelos de erosão são específicos para representar um ou, no máximo, dois tipos de erosão. Para algumas situações de solo e relevo, a erosão que ocorre no canal fluvial, em ravinas e voçorocas podem ser mais importantes ou preponderantes sobre a erosão entressulco e em sulco. Nesse caso, aplicar um modelo do tipo USLE, que estima os processos erosivos do tipo entressulcos e em sulcos, seria insuficiente. Uma alternativa para identificar os prováveis locais de ocorrência de erosão em ravinas e no canal fluvial poderia ser através da estimativa de forma especializada do índice potência do escoamento, definido por BAGNOLD (1966) e YANG (1972). A potência do escoamento $(\Omega)$ é definida como a taxa de energia expedida no tempo para realizar a desagregação e o transporte de sedimentos, ou seja, é uma medida do poder erosivo da água em movimento.
A potência do escoamento matematicamente é definida por: $\Omega=\rho \mathrm{g} \mathrm{q} \tan \beta$

em que é a potência do escoamento $\left(\mathrm{kg} \mathrm{m}^{-1} \mathrm{~s}^{-2}\right) ; \rho$ é o peso específico da mistura de água e sedimentos $(\mathrm{kg}$ $\left.\mathrm{m}^{-3}\right)$; g é a aceleração da gravidade $\left(\mathrm{m}^{2} \mathrm{~s}^{-1}\right) ; q$ é a vazão específica por unidade de largura $\left(\mathrm{m}^{2} \mathrm{~s}^{-1}\right)$; e $\beta$ a declividade $\left(\mathrm{m} \mathrm{m}^{-1}\right)$.

Além dos estudos de erosão e produção de sedimentos, a potência de escoamento é importante para a modelagem geomorfológica na simulação da formação de canais preferenciais de escoamento, importante no estudo da evolução das vertentes e formação de bacias de ordem zero. Para os estudos ambientais, a modelagem dos canais preferenciais do escoamento é importante para simular as rotas de transferência de poluentes, mecanismos de conexão entre fonte do poluente e os corpos d'água e taxa de transferência de contaminantes.

A potência de escoamento é uma variável de difícil medição, dificultando a aplicação dos modelos; alternativamente, é utilizado um índice topográfico que permite estimá-lo com boa precisão (MOORE et al., 1988). Oíndice $\Omega_{\mathrm{IT}}$ (índice topográfico da potência de escoamento) é calculado pelo produto entre a área de contribuição específica e a declividade:

$$
\Omega_{\mathrm{IT}}=\mathrm{A}_{\mathrm{s}} \tan \beta
$$

em que ${ }_{\text {IT }}$ é o índice topográfico da potência de escoamento. Esse índice é uma medida do poder erosivo da água em movimento, supondo que a vazão específica por unidade de largura $(q)$ é proporcional a $A_{s}$ e que o peso específico do escoamento permanece constante. Esse índice, combinado com a curvatura no perfil, pode ser associado à intensidade do processo erosivo. Assim, quando a curvatura no perfil é convexa (zonas de aceleração do escoamento) indica uma condição de maior suscetibilidade à desagregação e ao transporte de sedimentos, enquanto que nas áreas de curvatura no perfil côncavo (zonas de decréscimo de velocidade do escoamento) indica áreas preferências de ocorrência de processos deposicionais.

Com o objetivo de exemplificar a utilização desse índice, a potência do escoamento foi estimada na mesma bacia em que foi apresentado o exemplo da aplicação do cálculo do fator LS. Nessa bacia, as características fisiográficas favorecem o escoamento concentrado com alta energia de escoamento (relevo ondulado com presença frequente de encostas convexas). Sendo assim, quando a potência do escoamento apresentarem valores numéricos mais elevados, isso indicará áreas de maior risco ao aparecimento de canais de erosão e ravinas.

Em relação à conservação de córregos, riachos e rios, o índice de potência de escoamento pode 
ser utilizado para identificar trechos de rios de maior propensão à erosão (leito e margens). Na figura 2, são apresentados os valores do índice na bacia em que se verifica que os maiores valores são encontrados ao longo da rede de drenagem. Valores muito altos $(>3,6)$ ocorrem próximo ao exutório, em que tem sido constatado um aprofundamento crescente do leito, devido à erosão através de levantamentos topobatimétricos anuais. Nota-se também que os valores mais altos estão concentrados próximos aos talvegues em zonas de convergência de fluxo e em pendentes declivosas e convexas no terço inferior da bacia. Pendentes divergentes e côncavas apresentam valores baixos da potência de escoamento.

As áreas claras indicam valores baixos da potência do escoamento, o que estaria associado às áreas com menor potencialidade para a ocorrência de erosão por fluxo de escoamento concentrado. As áreas com valores intermediários indicam que, para as glebas cultivadas com culturas anuais, é necessário a implementação de práticas mecânicas de conservação de solo (terraços, cordões vegetados, canais vegetados, etc.). As áreas com tonalidades mais escuras salientam os locais na bacia onde a energia do escoamento atua com maior intensidade, indicando locais em que o processo erosivo pode ocorrer de maneira mais intensa, o que indica a necessidade de práticas destinadas a aumentar a estabilidade da calha fluvial através do manejo do ambiente ripário. Os valores mais altos abrangem pendentes de alta declividade localizadas no terço inferior da bacia. Algumas dessas áreas estão ocupadas com lavouras, indicando um evidente conflito de uso. Essas áreas deveriam ser destinadas à preservação permanente ou atividades de

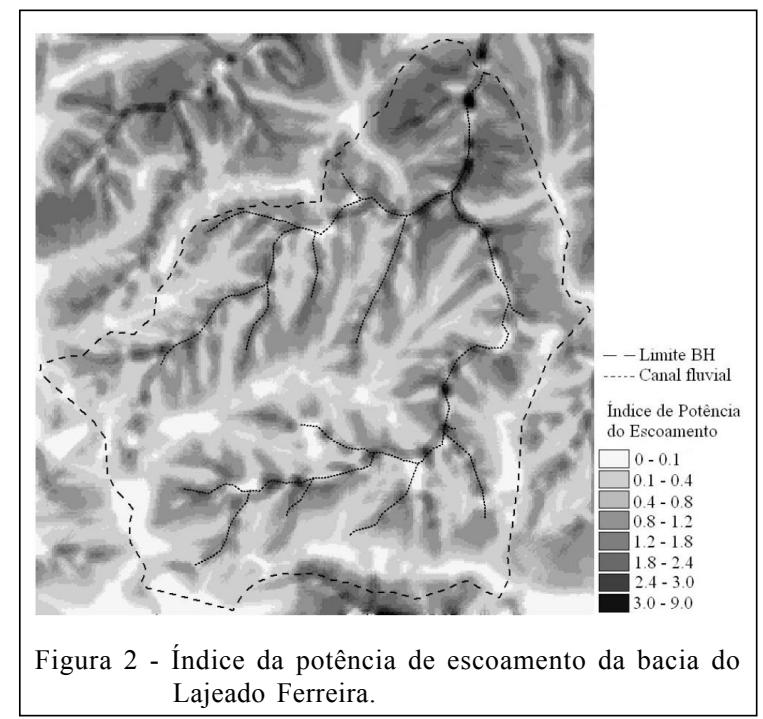

reflorestamento ou fruticultura, aliadas a práticas mecânicas de controle da enxurrada. Além disso, é essencial a preservação de mata ciliar para reduzir a erosão fluvial.

c) Determinação do índice de umidade do terreno

$O$ índice de umidade do terreno foi desenvolvido por BEVEN \& KIRKBY (1979) para o modelo hidrológico TOPMODEL, a fim de possibilitar a simulação das áreas de afluência variável (zonas saturadas) em áreas de relevo complexo. A saturação da superfície do solo ocorre, em geral, nas áreas de convergência do relevo e próximas aos canais de drenagem. Essas zonas saturadas se expandem e se retraem em reposta à precipitação e ao movimento subsuperficial da água de montante. As características topográficas da bacia são o fator controlador no mecanismo de movimento lateral e subsuperficial da água e a distribuição do conteúdo de água no solo dentro da bacia (BEVEN et al., 1988; MOORE et al., 1990). O índice de umidade do terreno também tem sido utilizado, combinado com a utilização do parâmetro $\mathrm{CN}$ (curva número) da equação de geração do escoamento do Soil Conservation Service (SCS) (LYON et al., 2004; SCHNEIDERMAN et al., 2007).

O índice de umidade do terreno $(u)$ é um atributo secundário, calculado com a área de contribuição específica $\left(\mathrm{A}_{\mathrm{s}}\right)$ e com o gradiente local $(\tan \beta)(B E V E N \&$ KIRKBY, 1979; MOORE et al., 1991; WILSON \& GALLANT, 1996), sendo a expressão definida como:

$$
u_{T}=\ln \left(\frac{A_{s}}{T \tan \beta}\right) \text { ou } u=\ln \left(\frac{A_{s}}{\tan \beta}\right)
$$

em que $T$ é a transmissividade que representa a integral da condutividade hidráulica saturada, quando o perfil do solo está saturado (O’LOUGHLIN, 1981, 1986).

Utilizando-se a mesma bacia dos exemplos anteriores, o índice de umidade do terreno foi calculado para indicar os locais de maior umidade de água no solo e áreas saturadas. Áreas úmidas e saturadas, como banhados e as planícies coluviais, apresentam uma importante função hidrológica (BRASKERUD, 2002). Apesar de representarem pequena extensão relativa ao tamanho da bacia, essas áreas assumem um papel fundamental no regime hidrológico da bacia, por exemplo, a recarga de aquíferos e a atenuação da onda de cheia através do amortecimento do escoamento superficial e subsuperficial.

Conforme tem sido possível verificar nos trabalhos que vem sendo realizados nessa bacia, verificados nos levantamentos a campo, os resultados gerados pelo índice de umidade do terreno (Figura 3) 
representam, de maneira muito apropriada, as áreas mais úmidas. De acordo com a figura 3, as áreas mais escuras representam os banhados e as planícies coluviais úmidas, formadas particularmente em pendentes de curvatura no perfil do tipo côncava. As cores intermediárias representam as pendentes de curvatura no plano do tipo convergentes em que os fluxos tendem a se concentrar, aumentando a umidade do solo; essas áreas estão presentes, principalmente, no terço superior e médio da bacia.

$\mathrm{Na}$ figura 3, identificam-se as zonas de saturação importantes para a geração do escoamento superficial (cores mais escuras). Essas áreas apresentam um comportamento hidrológico e de armazenamento de água distintos na bacia. Tal classificação pode servir como base para o planejamento agrícola e ambiental da bacia. As áreas com valores altos de umidade deveriam ser consideradas como áreas hidrologicamente $\mathrm{e}$ ecologicamente frágeis e deveriam ser preservadas, tendo em vista a importância na regulação hidrológica da bacia, na retenção de sedimentos e poluentes e na preservação da biodiversidade. As áreas com tonalidades intermediárias apresentam uma maior disponibilidade hídrica e estariam aptas para culturas de maiores necessidades hídricas. As áreas com tonalidades claras, de menor capacidade de armazenamento de água, seriam recomendadas para culturas de menor exigência hídrica. Áreas em branco representariam áreas com maior risco, devido à menor capacidade de armazenamento de água pelos solos, sendo então recomendadas para culturas resistentes a secas. Os limites sugeridos para as classes da figura 3

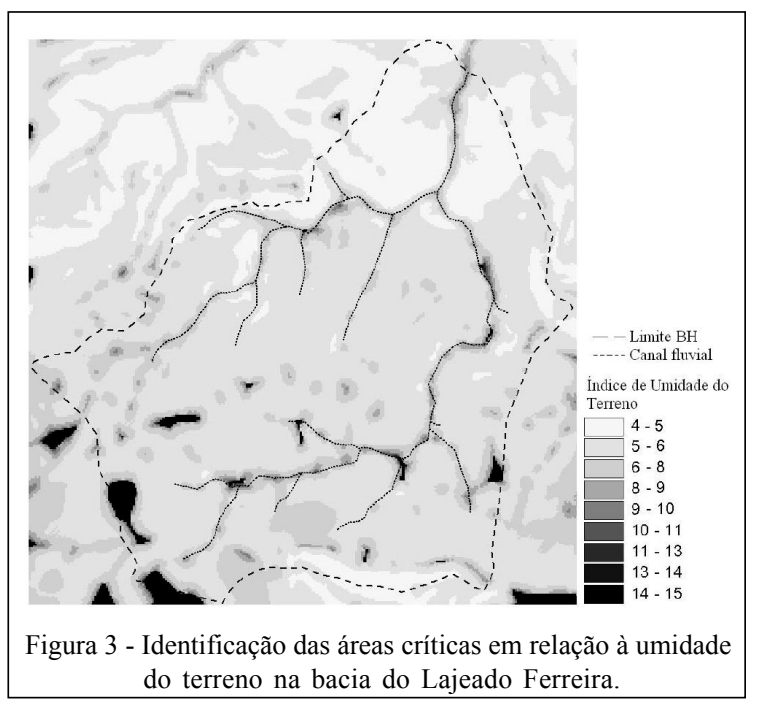

poderiam ser validados com o acompanhamento da análise da umidade do solo após eventos de chuva e durante estiagens, conforme se verifica nos trabalhos deCHAPLOT \& WALTER(2003), CHANG \& LEE(2008) eDETTY \& MCGUIRE (2010).

Conforme verificado, o índice de umidade, quando utilizado no planejamento agrícola e ambiental, serviria para orientar a utilização de áreas agrícolas com relação à disponibilidade hídrica e da necessidade de irrigação e, evidentemente, auxiliaria na identificação de áreas importantes para a preservação dos recursos hídricos.

\section{CONSIDERAÇÕES FINAIS}

A abordagem realizada neste trabalho mostra que a utilização de índices topográficos representa uma enorme contribuição para o planejamento agrícola e ambiental através da modelagem de processos hidrológicos, geomorfológicos e biológicos. Variáveis que são difíceis de serem medidas a campo podem indiretamente ser relacionadas com esses índices e então espacialmente estimadas sobre superfície de relevos complexos. Por outro lado, é necessário considerar de que as informações extrapoladas a partir desses índices necessitam ser validadas a campo. $\mathrm{O}$ estabelecimento de "áreas piloto" e o seu monitoramento podem contribuir para a redução das incertezas relacionadas com a utilização dos índices.

\section{REFERÊNCIAS}

ARONOFF, S. Geographic information systems: a management perspective. 4.ed. Ottawa: WLD Publications, 1995. 294p.

BAGNOLD, R.A. An approach to the sediment transport problem for general physics. Washington: US Gov. Print Office, 1966. (U.S. Geological Survey Professional Paper, n. 442-I).

BENATTO, L. et al. Estimativa de perda de solo através da equação universal de perdas de solo considerando diferentes cenários de manejo do solo. In: ENES, 7. Sedimentos: o desafio da multidisciplinaridade. Porto Alegre: ABRH, 2006. p.358-366.

BEVEN, K.J.; KIRKBY, M.J. A physically based, variable contributing area model of basin hydrology. Bulletin of Hydrological Sciences, v.24, p.43-69, 1979.

BEVEN, K.J. et al. On hydrological heterogeneity - catchment morphology and catchment response. Journal of Hydrology, v.100, p.353-375, 1988. Disponível em: <http:// dx.doi.org.ez47.periodicos.capes.gov.br/10.1016/00221694(88)90192-8>. Acesso em: 05 jun. 2009. doi: 10.1016/ 0022-1694(88)90192-8.

BRASKERUD, B.C. Factors affecting nitrogen retention in small constructed wetlands treating agricultural non-point source pollution. 
Ecological Engineering, v.18, p.351-370, 2002. Disponível em: $<$ http://www.sciencedirect.com.ez47.periodicos.capes.gov.br/ science>. Acesso em: 12 fev. 2011. doi: S0925857401000994.

BURROUGH, P.A. Principles of geographical information system for land resources assessment. Oxford: Claredon, 1987. 193p.

CHANG, C.; LEE, K.T. Analysis of geomorphologic and hydrological characteristics in watershed saturated areas using topographic-index thereshold and geomorphology-based runoff model. Hydrological Processes, v.22, p.802-812, 2008. Disponível em: <http:// onlinelibrary.wiley.com.ez47.periodicos.capes.gov.br/doi/10.1002/ hyp.6638/pdf>. Acesso em: 24 mar. 2009. doi: 10.1002/hyp.6638.

CHAPLOT, V.; WATER, C. Subsurface topography to enhance the prediction of the spatial distribution of soil wetness. Hydrological Processes, v.17, p.2567-2580, 2003. Disponível em: <http://onlinelibrary.wiley.com.ez47.periodicos.capes.gov.br/ doi/10.1002/hyp.1273>. Acesso em: 30 ago. 2010. doi: 10.1002/ hyp. 1273 .

DETTY, J.M.; McGUIRE, K.J. Topographic control on shallow groundwater dynamics: implications of hydrologic connectivity between hillslope and riparian zones in a till mantled catchment. Hydrological Processes, v.24, p.2222-2236, 2010. Disponível em: <http://onlinelibrary.wiley.com.ez47.periodicos.capes.gov.br/ doi/10.1002/hyp.7656/pdf>. Acesso em: 15 jun. 2011. doi: $10.1002 /$ hyp. 7656 .

FLORINSKY, I.V. Relationships between topographically expressed zones of flow accumulation and sites of fault intersection: analysis by means of digital terrain modeling. Environmental Modelling \& Software, v.15, p.87-100, 2000. Disponível em: <http:// www.sciencedirect.com.ez47.periodicos.capes.gov.br/science/ article/pii/S1364815299000250>. Acesso em: 02 fev. 2011. doi: S1364815299000250.

LONGLEY, P.A. et al. Geographic information systems and science. 2.ed. Chichester: Wiley, 2005. 497p.

LYON, S.W. et al. Using a topographic index to distribute variable source area runoff predicted with the SCS curve-number equation. Hydrological Processes, v.18, p.2757-2771, 2004. Disponível: $<$ http://onlinelibrary.wiley.com.ez47.periodicos.capes.gov.br/doi/ 10.1002/hyp.1494/pdf>. Acesso em: 14 set. 2009. doi: 10.1002/ hyp. 1494.

MEIRELLES, M.S.P. et al. Geomática: modelos e aplicações ambientais. Brasília: Embrapa, 2007. 593p.

MENDES, C.A.B.; CIRILO, J.A. Geoprocessamento em recursos hídricos: princípios, integração e aplicação. Porto Alegre: ABRH, 2001. 535p.

MERTEN, G.H.; MINELLA, J.P.G. Monitoramento hidrossedimentométrico e da qualidade de água da Microbacia de Arvorezinha. - Relatório do Projeto de Monitoramento Ambiental de Microbacias Hidrográficas do Programa RS-RURAL. Porto Alegre: IPH/UFRGS, 2005. 59p.

MINELLA, J.P.G. et al. Utilização de métodos de representação espacial para cálculo do fator topográfico na equação universal de perda de solo revisada em bacias hidrográficas. Revista Brasileira de Ciência do Solo, v.34, p.1455-1462, 2010. Disponível em: $<$ http://www.scielo.br.ez47.periodicos.capes.gov.br>. Acesso: 12 nov. 2010. doi: 06832010000400041.
MOORE, I.D.; BURCH, G.J. Modeling erosion and deposition: topographic effects. Transactions of the ASAE, v.29, n.6, p.1624-1630, 1986a.

MOORE, I.; BURCH, G. Physical basis of the length-slope factor in the universal soil loss equation. Soil Science Society of America Journal, v.50, p.1294-1298, 1986b.

MOORE, I.D. et al. Topographic effects on the distribution of surface soil water and the location of ephemeral gullies. Transactions of the ASAE, v.31, p.1098-1107, 1988.

MOORE, I.D. et al. Runoff modelling in complex threedimensional terrain. IAHS Publication, v.193, p.591-599 1990.

MOORE, I.D. et al. Digital terrain modeling: a review of hydrological, geomorfological and biological applications. Hydrological Processes, v.5, p.3-30, 1991.

MORGAN, R.P.C. Soil erosion and conservation. Longman science and technical. 2.ed. Wiley: New York, 2005. 198p.

O'LOUGHLIN, E.M. Saturation regions in catchments and their relations to soil and topographic properties. Journal of Hydrology, v.53, p.229-246, 1981. Disponível em: <http:// dx.doi.org. ez47.periodicos.capes.gov.br/>. Acesso em: 08 mar. 2010. doi: 10.1016/0022-1694(81)90003-2.

O'LOUGHLIN, E.M. Prediction of surface zones in natural catchments by topographic analysis. Water Resources Research, v.22, n.5, p.785-804, 1986.

QUINN, F. The $\ln (\alpha / \tan \beta)$ index: How to calculate it and how to use it within the Topmodel framework. Hydrological Processes, v.9, p.161-182, 1995.

RENARD, K.G. et al. Predicting soil erosion by water - A guide to conservation planning with revised universal soil loss equation (RUSLE). Washington D.C.: US Gov. Print Office, 1997. 384p.

RICHERSON, P.J.; LUM, K. Patterns of plant species diversity in California: relation to weather and topography. American Naturalist, v.116, n.4, p.504-536, 1980 .

SCHNEIDERMAN, E.M. et al. Incorporating variable source area hydrology into a curve-number-based watershed model. Hydrological Process, v.21, p.3420-3430, 2007. Disponível em: <http://onlinelibrary.wiley.com.ez47.periodicos.capes.gov.br/ doi/10.1002/hyp.6578/pdf>. Acesso em: 25 ago. 2009. doi: $10.1002 /$ hyp. 6578 .

WILSON, J.P. et al. EROS: A grid-based program for estimating spatially-distributed erosion indices. Computers \& Geosciences, v.22, p.707-712, 1996. Disponível em: <http:/ /www.sciencedirect.com.ez47.periodicos.capes.gov.br/science/ article/pii/0098300495000976>. Acesso em: 22 maio, 2009. doi: 10.1016/0098-3004(95)00097-6.

WISHMEYER, W.H.; SMITH, D.D. Predicting rainfall erosion losses: a guide to conservation planning. Washington: USDA Agricultural Handbook, 1978. 58p.

YANG, C.T. Unit stream power and sediment transport. ASCE Journal of the Hydraulics Division, v.98, p.1805-1826, 1972. 